\title{
RE/DES/CONSTRUINDO IN/DIFERENÇAS: A EXPULSÃO COMPULSÓRIA DE ESTUDANTES TRANS DO SISTEMA ESCOLAR
}

\author{
Isaias Batista de Oliveira Junior \\ Eliane Rose Maio**
}

\begin{abstract}
RESUMO
Estudantes Trans(E.T.) - Travestis, Transexuais e Transgêneros - são vítimas do processo de heteronormatização ao arquitetarem seus corpos em conformidade com sua identidade de gênero. A escola, agente dessa colonização, acaba por afastar do seu interior E.T. por meio da expulsão compulsória, invisibilizada sob o manto do fracasso escolar. Buscando subsidiar estes apontamentos, assumimos como objetivo central descrever a construção da identidade de E.T. e como a cultura da diferença é re/produzida no contexto escolar apresentando recortes de uma pesquisa realizada com educadores(as) para a obtenção do título de mestre, sustentada na teoria dos Estudos Culturais. Os dados obtidos apontaram que as fobias das quais alunos(as) homossexuais são vítimas assumem fórum de agravamento quando destinadas a E.T. Essa transfobia consiste na estigmatização e retirada de direitos básicos, como o reconhecimento do nome social, livre acesso a espaços no interior da escola e uso de sanitários ao gênero que se identifica. Concluímos que a adoção de estratégias que discutam a identidade de gênero, violência de gênero, transfobia, manifestações das sexualidades, dentre outros, devem fazer parte do cotidiano escolar de forma a envolver todos os seus agentes no combate à violência imputada a E.T., promovendo a cultura do respeito para com as diferenças.
\end{abstract}

Palavras-chave: Identidades. Diferenças. Heteronormatização. Estudantes Trans. Escola.

\section{ABSTRACT \\ RE/UN/BUILDING IN/DIFFERENCES: THE COMPULSORY EVICTION OF STUDENTS TRANS OF THE SCHOOL SYSTEM \\ Trans students (E.T.) - Transvestites, Transsexuals and Transgender - are victims of hetero normalization process when constructing their bodies in accordance with their gender identity. The school, active agent of this colonization, ends up pushing them away from their E.T. interior through the compulsory eviction, unnoticed under the}

\footnotetext{
* Doutorando em Educação pela Faculdade de Ciência e Tecnologia da Universidade Estadual Paulista (UNESP). Mestre em Educação pela Universidade Estadual de Maringá (UEM). Professor da Universidade Estadual do Paraná (UNESPAR/FECEA). Bolsista CAPES/CNPQ. Membro do Núcleo de Pesquisa e Estudos sobre Diversidade Sexual da Universidade Estadual de Maringá.jr_oliveira1979@hotmail.com

** Pós-Doutora em Educação Escolar pela Universidade Estadual Paulista (UNESP/Araraquara). Professora do Programa de Pós-Graduação em Educação da Universidade Estadual de Maringá (PPE/UEM). Coordenadora do Grupo de Estudos Núcleo de Pesquisa e Estudos sobre Diversidade Sexual, da Universidade Estadual de Maringá. elianerosemaio@yahoo.com.br
} 
cloak of school failure. In order to provide these inputs, we assume as central objective to describe the construction of E.T. identity and how the culture of difference is re/ produced in school context presenting cutouts of a research performed with educators, to obtain the title of master, supported by the theory of Cultural Studies. The collected data showed that the phobias of which homosexual students are victims, take worsening forum when intended for E.T. This transphobia consist on the stigmatization and deprivation of basic rights such as the recognition of the social name, free access to spaces within the school and use of toilets according to the genre that identifies. We conclude that the adoption of strategies to discuss gender identity, gender violence, transphobia, manifestations of sexualities, among others, should be part of everyday school life in order to involve all its agents in fighting violence attributed to E.T. promoting the culture of respect for differences.

Keywords: Identity. Differences. Heteronormativity. Trans students. School.

\section{RESUMEN}

\section{RE/DES/CONTRRUYENDO IN/DIFERENCIAS: LA EXPULSIÓN OBLIGATORIA DE ESTUDIANTES TRANS DEL SISTEMA ESCOLAR}

Estudiantes Trans(E.T.) - Travestis, Transexuales y Transgénero - son víctimas de proceso de hetenorma lización al construir sus cuerpos de acuerdo con su identidad de género. La escuela, agente de colonización E.T., acaba por colocarlo lejos de su interior a través de la expulsión obligatoria invisible bajo el manto del fracaso escolar. Para argumentar estos apuntes, asumimos como objetivo central describir la construcción de la identidad E.T. y como la cultura de la diferencia es re/producido en el contexto escolar, presentamos fragmentos de una investigación con educadores/as para obtener el título de maestría, sustentada en la teoría de Estudios culturales. Los datos mostraron que las fobias de las cuales los estudiantes homosexuales son víctimas, asumen foro de gravedad cuando están destinadas a E.T. Esa transfobia consiste en la estigmatización y eliminación de los derechos básicos, como el reconocimiento del nombre social, el libre acceso a los espacios dentro del la escuela y el uso de inodoros del género al cual se identifica. Llegamos a la conclusión de que la adopción de estrategias para discutir la identidad de género, la violencia de género, la transfobia, manifestaciones de la sexualidad, entre otros, debe ser parte de la vida cotidiana de la escuela con el fin de involucrar a todos sus agentes en la lucha contra la violencia atribuida a la E.T., promoviendo la cultura de respeto a las diferencias.

Palabras claves: Identidad. Diferencias. Heteronormatividad. Estudiantes Trans. Escuela.

\section{Introdução}

Na contemporaneidade, a sociedade em geral, o Estado, as culturas midiáticas, as leis, a religião, a escola, dentre outras instituições, reiteradamente perpetuam em suas estratégias as matrizes identitárias tidas como referências e, consequentemente, fortalecem a re/produção das diferenças. Dentre as dinâmicas estabelecidas por estas instituições, podemos citar um processo denominado de heteronormatização, que embora pouco debatido, tem sua prática bastante difundida em nossa sociedade por estes organismos.

A heteronormatização é um des/serviço empregado na consolidação do imperativo heterossexual em detrimento de outras formas de manifestações da sexualidade e da materialização de normas regulatórias que são, em partes, aquelas da hegemonia 
heterossexual normativa. Esta acaba por receber um valor positivo e privilegiado, enquanto as que se distanciam desta matriz são fortemente desvalorizadas (LIONÇO; DINIZ, 2009).

Recentemente, tal prática foi observada na mídia, como noticiavam as câmaras legislativas que tentaram aprovar a discussão de gêneros em seus Planos Municipais de Educação, nos recintos públicos do Brasil. De um lado, defensores(as) do movimento tentavam convencer líderes partidários da necessidade de incluir a temática nos Planos Escolares; de outro lado, líderes políticos e religiosos arguiam a favor da biologização humana, centrada na masculinidade e na feminilidade. Nesse embate venceu o conservadorismo.

Tendo esse cenário como plano de fundo, o quotidiano de Estudantes Trans (E.T. $)^{1}$ — Travestis, Transexuais e Transgêneros - tende a ser vigiado constantemente pelos dispositivos da sexualidade em ação, "que institui e destitui identidades, dita comportamentos, práticas, representações e, sobretudo, auto representações" (SWAIN, 2009, p. 01). Essa prática é firmada no discurso midiático, nas pseudociências, na Psicanálise, na repetição de imagens estereotipadas, em modelos de ajuste, padrões de conduta e valores de ajuste social e pertencimento a um grupo (SWAIN, 2009).

$\mathrm{Na}$ tentativa de evidenciar o cotidiano escolar de parte dos(as) E.T., fizemos o recorte de uma pesquisa realizada para a obtenção do título de Mestre em Educação, desenvolvida em escolas da Rede Pública de Ensino Médio de 13 Municípios do Estado do Paraná, no período compreendido entre 2012 e 2013, intitulada $O / A$ diretor/a não viu, a pedagoga não ouviu e a professora não quer falar: discursos docentes sobre diversidade sexual, homofobia e "Kit Gay" (OLIVEIRA JÚNIOR, 2013). Sustentamos nossas análises nas falas obtidas através de entrevistas semiestruturadas com 12 diretores(as) escolares, 12 pedagogas e 13 docentes de Biologia. Recorremos à entrevista semiestruturada e à análise de conteúdo, proposta por Bardin (2010), por acreditarmos no seu poten-

1 A adoção dessa expressão pode ser interpretada ambiguamente e, de fato, é essa a intenção, ao evidenciar que os/as "E.T." são vistos(as) como "extraterrestres" pela comunidade escolar. Por outro lado, é uma forma de sintetizar e evitar repetições excessivas ao nos referirmos a alunos(as) Travestis, Transexuais e Transgêneros, o que cansaria o/a leitor(a) cial de fornecer as representações livres daquilo que essas pessoas vivenciam, sentem e pensam sobre a identidade de gênero e as diferenças.

É válido ressaltar que esse não era o objetivo central do processo dissertativo, que possuía como foco o estudo da diversidade sexual, homofobia e Kit de Combate e Prevenção a Homofobia do Ministério da Educação e Cultura. Não prevista inicialmente como uma das diretrizes norteadoras da nossa pesquisa, a Transfobia pedagógica chamou nossa atenção pela sua constância em meio às discussões realizadas, o que nos levou a concluir que os/as E.T. são estigmatizados no contexto educacional pela comunidade escolar em geral e, diante desse cenário de hostilidade, acabam se evadindo desse espaço. Essa evasão acaba sendo invisibilizada pelo corpo docente, por conta do não acompanhamento escolar destes(as) estudantes.

Justificada a escolha da temática, adotamos como objetivo geral para este estudo descrever a construção da identidade de E.T. e como a cultura da diferença se re/produz no contexto escolar. A partir daí desdobram-se os objetivos específicos, quais sejam: caracterizar a construção da identidade de gênero de pessoas Trans; evidenciar a transfobia pedagógica nos ritos escolares mediante a não adoção do nome social, ou a terceirização de espaços comuns no ambiente escolar; e demonstrar os reflexos da pedagogia transfóbica na expulsão compulsória de E.T., camuflada sob o pretexto de fracasso escolar.

Utilizando esses objetivos como ponto de partida, buscamos respaldo na teoria dos Estudos Culturais proposta por Stuart Hall (2006, 2007) e Tomaz Tadeu da Silva (2007). Sendo assim, dentro das possíveis limitações conceituais, explicitaremos a seguir como a vertente da construção da(s) identidade(s) e da(s) diferença(s) heteronormativa(s) ocorre no âmbito escolar, sendo necessário apresentarmos inicialmente o conceito de identidade de gênero, o que optamos momentaneamente por denominar de processo de generificação. Em seguida, abordaremos a chegada, permanência e evasão dos(as) "E.T." na escola, encerrando com breves apontamentos para além de uma conclusão definitiva sobre o assunto em tela. 


\section{Identidade de gênero ou generificação: um breve debruçar}

A identidade de gênero, como quaisquer outros aspectos da vida dos seres humanos, carrega em sua essência pressupostos históricos, antropológicos e culturais, e "[...] todo este jogo de diferenças é prescrito pela função do autor, tal como a recebe de sua época ou tal como ele, por sua vez, a modifica" (FOUCAULT, 2007, p. 29).

O estudo descritivo de "gênero" foi historicamente associado ao conceito das coisas relativas às mulheres. Porém, na pós-modernidade, sua conceituação tem sido empregada numa variedade de abordagens na análise do gênero e desenvolvimento da sexualidade, e uma das suas aplicabilidades é

[...] anterior à emergência do humano, ao considerar uma criança, por exemplo, de um ser 'neutro' para um 'ele ou ela', torna a garota uma garota e a traz para o domínio da linguagem e do parentesco através da interpelação fundante de gênero. Porém, esse tornar-se garota, não se encerra na sua concepção ou nascimento, mas é reiterada por várias autoridades [o que denominamos de heteronormatização compulsória], ao longo de vários intervalos de tempo, na tentativa de reforçar ou contestar esse efeito naturalizado. Essa nomeação é, ao mesmo tempo, $o$ estabelecimento de uma fronteira e também a inculcação repetida de uma norma. (BUTLER, 2010, p. 161, grifo do autor).

No decorrer desse processo de normalização associado e de construção social do sexo biológico foi estabelecido o conceito de gênero com o intuito de distinguir a dimensão anatômica biológica da dimensão social, baseando-se no raciocínio de que há machos e fêmeas na espécie humana.

Sendo assim,

[...] a maneira de ser homem e de ser mulher é realizada através de inúmeras aprendizagens e práticas, nas mais distintas situações, empreendida de modo explícito ou dissimulada por um conjunto inesgotável de instâncias sociais e culturais. É um processo minucioso, sutil, sempre inacabado. Família, escola, igreja, instituições legais e médicas mantêm-se, por certo, como instâncias importantes nesse processo constitutivo. (LOURO, 2008, p. 18).

Tais aspectos implicam diretamente no modo como homens e mulheres se comportam; há uma expectativa social em relação à forma como "[...] homens e mulheres devem andar, falar, sentar, mostrar seu corpo, brincar, dançar, namorar, cuidar do outro, amar, trabalhar, gerenciar outras pessoas, ensinar, dirigir o carro, gastar o dinheiro, ingerir bebidas, dentre outras atividades" (BRASIL, 2009, p. 40).

As normas reguladoras são incorporadas aos discursos da sexualidade e de gênero e influenciam na construção de mulheres e homens como tipos diferentes de indivíduos.

Essas pessoas marcadas por gênero corporificam diferentes princípios de agência [...] onde a sexualidade masculina e pessoas do gênero masculino são retratadas como ativas, agressivas, impositivas e poderosas, enquanto que a sexualidade feminina e pessoas do gênero feminino são vistas como essencialmente passivas, fracas, submissas e receptivas. Esses discursos marcados por gênero são em todos os casos construídos através da imbricação mútua com diferenças de raça, classe, etnicidade e religião. (MOORE, 2000, p. 16).

Essas marcações, reflexos da heteronormatização, consideram a identidade de gênero como algo dado. Contrariamente a esse posicionamento, defendemos que o gênero é constituído e vivenciado ativamente por cada homem e mulher a partir dos elementos fornecidos por sua cultura, ou pelo fato de alguém avesso ao seu sexo biológico sentir-se masculino e/ou feminino, num processo dinâmico e contínuo.

Dito de outra forma, a identidade de gênero não se encerra com o nascimento, mas começa a partir deste marco ou anteriormente, durante o ultrassom para identificar o sexo biológico do bebê, por meio de uma construção cultural/social e histórica, uma aquisição, uma performance, uma atuação. Há de se afirmar que não há um elo imediato e inescapável entre os cromossomos, o órgão genital, o aparelho reprodutor, os hormônios; enfim, o corpo biológico em sua totalidade e o sentimento que a pessoa possui de ser homem ou mulher (BUTLER, 2009; MOORE, 2000).

Parafraseando Beauvoir (1980), de que não nascemos homens, nem mulheres, mas nos tornamos um(a) deles(as), estamos reiterando o não determinismo biológico, pois acreditamos que a vivência da identidade de gênero inclui fatores de naturezas 
distintas combinados com o aprendizado, a descoberta e a invenção, portanto ela “[...] é estruturante da trajetória pessoal e constitui-se na complexa combinação de muitos elementos de cunho subjetivo e da relação com o outro. Isso ocorre desde o nascimento a partir da sexuação e da erotização do corpo [...]" (SAYÃO, 1997, p. 113-114).

Não sendo a construção identitária determinada biologicamente, temos aqueles indivíduos que ultrapassam as fronteiras do binarismo de gênero macho/fêmea, masculino/feminino, ditos indivíduos Trans, ou pessoas Travestis, Transexuais e Transgêneras. Estas pessoas se identificam como do sexo oposto em uma base temporária ou permanente e que convivem harmoniosamente ou conflituosamente com o sexo biológico dado com o nascimento. Há de se considerar que esses sujeitos podem, por um breve período de tempo, se sentir pertencentes aos gêneros masculino e feminino - bigêneros - ou a nenhum deles - agêneros (BUTLER, 2010; MOORE, 2000).

A forma como eles(as) percebem sua identidade de gênero inclui o senso pessoal do corpo, que poderá sofrer alterações, por livre escolha, que variam desde as modificações estéticas ou anatômicas, através de intervenções médicas ou cirúrgicas, ou outras formas mais sutis e transitórias, como tratamentos hormonais. Isso está ligado diretamente à nossa identidade de gênero, por tratar-se da forma como nos vemos e queremos ser vistos(as), reconhecidos(as) e respeitados(as), como homens ou como mulheres, independentemente do sexo biológico (GATTI, 2003).

Dessa forma, dentre o gradiente das sexualidades

[...] não há uma única feminilidade ou masculinidade com que as mulheres e homens individuais possam se identificar em seus contextos sociais, mas sim uma variedade de feminilidades e masculinidades possíveis fornecidas pelos discursos concorrentes e contraditórios que existem, e que produzem e são reproduzidos por práticas e instituições sociais. (MOORE, 2000, p. 35).

Reiteramos então que "[...] não é o momento do nascimento e da nomeação de um corpo como macho ou como fêmea que faz deste um sujeito masculino ou feminino [...]" (LOURO, 2008, p. 18). A construção e manifestação do gênero e das sexualidades dão-se ao longo de toda a vida, continuamente, infindavelmente, “[...] transformando-se não apenas ao longo do tempo, historicamente, como também na articulação com as histórias pessoais, as identidades sexuais, étnicas, de raça, de classe [...]" (LOURO, 1997, p. 28).

Para Louro (2008, p. 17), fazer-se homem ou mulher depende de escolhas "[...] das marcas, dos gestos, dos comportamentos, das preferências e dos desgostos que lhes são ensinados e reiterados, cotidianamente, conforme normas e valores de uma dada cultura". O que consideramos masculino ou feminino é apenas o resultado de convenções sociais e não aquilo que cada um(a) vivencia individualmente na construção da sua identidade de gênero.

\section{Os/As E.T. invadem ou evadem da escola?}

A escola, em particular, é uma "“[...] instituição que nasceu disciplinar e normatizadora, a diferença, ou tudo aquilo que está fora da norma, em especial, a norma sexual, mostra ser insuportável por transbordar os limites do conhecido" (CÉSAR, 2009, p. 48), configurando-se num lugar de opressão no qual sujeitos LGBTQIA - Lésbicas, Gays, Bissexuais, Bigêneros, Travestis, Transexuais, Transgêneros, Queers, Questionadores(as), Intersexos, Indecisos(as), Assexuados(as) e Aliados(as) - vivem, de maneiras distintas, situações delicadas de vulnerabilidade, negação, autoculpabilização e internalização das fobias. Isso se faz com a participação ou omissão da família, da comunidade escolar, sociedade civil, Estado etc. (JUNQUEIRA, 2009; LIONÇO; DINIZ, 2009; OLIVEIRA JÚNIOR, 2013).

As fobias associadas ao ódio, medo, nojo, raiva, desconforto, aversão ou igualmente as "[...] tentativas de horrorizar, gerar pânico, amedrontar gays, lésbicas, travestis, transexuais, por suas condições e posições, e em circunstâncias diversas [...]" (SOUSA FILHO, 2013, p. 15) são um fenômeno social que atinge milhões de jovens e adultos(as) escolares e

[...] representam problemas reais que produzem e alimentam preconceitos, discriminações, violências 
e violações de direitos humanos. Geram, nas pessoas que são alvos desses mecanismos, mal-estar, insegurança, angústia, isolamento e sofrimento. Esses sentimentos podem interferir em suas relações sociais; prejudicar seu rendimento escolar, levando-as até a sair da escola; impedir seu acesso a oportunidades de emprego ou promoção no ambiente de trabalho; aumentar sua vulnerabilidade às DST/HIV/AIDS e ao uso de drogas, e influenciar em sua qualidade de vida e de saúde. (BRASIL, 2011, p. 22).

No ambiente escolar, em razão do status de privacidade que adquirem, essas fobias se traduzem em situações limites, como agressões físicas, ou desvelam-se em formas mais sutis, como atos de violência simbólica sinalizados em piadas, brincadeiras jocosas ou mesmo comentários e insinuações de desejo de afastamento de pessoas re/conhecidas ou supostamente identificadas como homossexuais. Logo, a prática discriminatória não afeta somente pessoas LGBTQIA, já que, comumente, desde que um indivíduo não corresponda ao processo de heteronormatização, passa a ser tratado como potencial homossexual e discriminado como tal (DINIS, 2011).

A LGBTQIAfobia ${ }^{2}$ impacta diretamente na esfera dos sentimentos, da dignidade, do sucesso ou do fracasso escolar. As agressões físicas e verbais, a destituição de esperanças, de sobrevivência digna, além das exclusões constantes às quais estes(as) alunos(as) são submetidos(as) corriqueiramente no cotidiano escolar, quando comumente são inferiorizados(as) ou reprimidos(as), criam situações tristes de constrangimentos, sofrimento psíquico intenso, o que impulsiona a saída dessas pessoas das escolas, dificultando seu acesso ao mercado de trabalho, obrigando-os(as) à sujeição de subempregos e atividades estigmatizantes (ABRAMAVOAY, 2009).

2 Adotamos a expressão LGBTQIAfobia com a intenção de sublinhar que a intransigência social em relação à homossexualidade masculina (ideia implícita à noção de homofobia) não é da mesma ordem do desrespeito que atinge lésbicas (oprimidas por uma lesbofobia que, além de homofóbica, é machista e sexista), nem do repúdio que sistematicamente atinge travestis e transexuais, cujas existências ferem de morte os binarismos macho-fêmea, homem-mulher, o que as tornam vítimas preferenciais do terrorismo de gênero. Acredita-se que, ao adotar um termo único, evita-se o uso repetitivo das expressões Lesbofobia, Transfobia, Travestifobia, Tansgênerofobia, Gayfobia, Bifobia, Bigênerofobia, Queerfobia, Intersexofobia, Aliadofobia e Assexofobia, o que cansaria o/a leitor(a) (SCHULMAN, 2013).
Essa pedagogia do insulto, que atinge homens e mulheres homossexuais de diversas formas e variadas intensidades e assume fóruns de agravamento em relação aos(às) E.T., caracterizada como transfobia pedagógica, é calcada no processo de heteronormatização ao estabelecer a construção de identidades mantendo o jogo das diferenças (JUNQUEIRA, 2012).

Os/As E.T. não passam incógnitos(as) pelo incômodo natural que apresentam ao conformismo generificado. Ao arquitetarem seus corpos, suas maneiras de apresentar-se, expressar-se e agir na escola, “[...] tendem a enfrentar obstáculos para se matricular, participar das atividades pedagógicas, ter suas identidades respeitadas, fazer uso das estruturas escolares (como os banheiros) e preservar sua integridade física" (JUNQUEIRA, 2012, p. 78 ), pois o discurso da escola é baseado naquilo que pode ser considerado como normal e desviante, colocando em xeque a própria humanidade e direitos daqueles(as) que ultrapassam as barreiras do binarismo de gênero masculino/feminino (BUTLER, 2010).

O sistema escolar não consegue alcançar a unidade almejada, pois há corpos que escapam ao processo de re/produção dos gêneros inteligíveis e imutáveis e da dicotomia hierarquizada; essa transgressão põe em risco toda uma estruturação, por desobedecer aos códigos de gênero e ao mesmo tempo revelar as possibilidades de transformação dessas mesmas normas (BENTO, 2011).

$\mathrm{Se}$ as normas educacionais preveem a escola como um local de inclusão, da convivência das diferenças e do acesso livre e democrático ao conhecimento, tais políticas não contemplam estudantes travestis, transexuais e transgêneros, que veem o contexto escolar como um local de penitências e aborto de possíveis conquistas sociais (SILVA, 2008).

Bohm (2009) corrobora essas informações trazidas ao entrevistar mulheres travestis sobre sua trajetória acadêmica, sendo que muitas delas afirmaram não ter dado prosseguimento aos estudos mediante as problemáticas com que se deparavam em seu cotidiano. Elas apontaram como impedimentos o simples ato para entrada na escola, o livre acesso a seus espaços previamente organizados não para elas - e a intransigência de grande parte 
da comunidade escolar acerca de sua permanência neste local.

Essas mulheres trans elencaram como dificuldades cotidianas no processo de escolarização a

[...] efetivação de matrícula, instituída a partir de ações intransigentes não observadas em relação às demais matrículas; relatam desde a imposição de regras de vestimenta ou de impedimentos para o uso do nome social até a submissão a um torturante cotidiano de piadas, agressões verbais e até mesmo físicas; denunciam o isolamento e a segregação impostos pelos colegas e também, muitas vezes, pelos professores. Tal contexto produz uma crescente tensão nas relações escolares, consistindo desafio muitas vezes sequer identificado como parte do trabalho escolar, no sentido de inclusão e permanência nas instituições de tais sujeitos. (BOHM, 2009, p. 59).

Esse processo de subterfúgio carcerário dos corpos sexuados é marcado por anseios, dores, conflitos e medos por parte dos(as) E.T., evidenciado no relato de uma pedagoga, como segue:

[...] a gente tem uma aluna, um aluno né [dá ênfase], que ela é do sexo, do gênero masculino mais que ela é feminino. Ela é toda feminina [...] têm dias que a gente percebe que ela sofre bastante. Não sei se porque ainda é nova né, ela tem 16 ou 17 anos agora [...] ela colocou pra gente: 'eu estou sendo discriminada'. Falei: 'vamos pensar diferente?' Eu vou fazer o quê? [...]. Por que como é que eu posso falar pra você que é discriminação? Será que não falta conhecimento? Eu não posso dizer que ela foi discriminada. (ESCOLA B, BRANCA,3 PEDAGOGA, GRIFOS NOSSOS).

Nessa alocução merece destaque o alheamento ao sofrimento de alunas travestis pela suposta "imaturidade", uma vez que as formas de violência às quais são submetidas no decorrer da sua trajetória acadêmica independem da idade. Outro ponto que nos chama atenção é o fato de que a escola não considera prematuros(as) aqueles(as) alunos(as) que manifestem identidades em conformidade com o binarismo de gênero na mais tenra idade.

No entanto, quando alunas travestis, aos dezessete anos de idade, se identificam como pertencendo ao gênero oposto ao que a cultura escolar lhe atribui, são consideradas jovens demais, precoces,

3 Vale ressaltar que por questões éticas os nomes apresentados são pseudônimos criados com a intenção de preservar a identidade dos(as) participantes da pesquisa e dos sujeitos citados vítimas do modismo e/ou da inexperiência. A adoção dessa conduta é amparada pela ausência de estratégias educacionais voltadas ao respeito e valoração das múltiplas formas de manifestações de gênero.

Outra situação manifesta na escola diz respeito aos ritos internos

[...] tenho um travesti, é o Gregório, que gosta de ser chamado de Melanie e ele se veste de mulher. Ele vem vestido de mulher. E agora vai ter formatura e eu perguntei pra ele: 'que jeito você quer ser chamado? Você vai de mulher ou de homem pra formatura?' 'Eu quero ir de mulher.' Falei: 'ótimo.' 'E me chame de Melanie.' 'Tudo bem, vou te chamar de Melanie.' Como que a sociedade na hora vai reagir? Não sei. Mas eu tenho que respeitar a vontade dele, isso que eu sei. Já tá conversado, beleza. (ESCOLA C, BRIGITTE, DIRETORA).

Tratar uma aluna travesti no masculino é o primeiro sintoma da falta de reconhecimento do gênero com o qual ela se identifica. Junqueira (2012) questiona por que é tão difícil e perturbador garantir o direito de uma pessoa ser tratada da forma em que ela se sente confortável e, sobretudo, humana, independente do lugar e da ocasião. É uma simples questão de respeito e humanidade e a réplica vem prontamente na eloquência da pedagoga dessa mesma unidade escolar.

[...] nós temos até um caso de um aluno de terceiro ano [...] o nome é Gregório e ele gostaria de ser chamado de Melanie na formatura. Mas aí tem toda uma legislação sobre isso, ele teria que ter 18 anos pra fazer essa opção né. Então ele gostaria de ser chamado pelo nome social [...] Eu digo: 'não, você vai ter que cumprir a lei, a lei é essa, porque você não tem 18 anos ainda. Não tem como a gente fazer isso pra você na formatura.' (ESCOLA C, BRIDA, PEDAGOGA).

Em tréplica, a diretora do colégio alega que, enquanto formadora de opinião, a escola não pode expor a aluna de forma a constrangê-la e deve promover na sociedade a cultura do respeito, caso contrário, a escola estará atuando como algoz e impedindo o seu livre acesso aos espaços e ritos escolares, tido como direito irrenunciável.

[...] é uma situação delicada, tem que sentar e tem que haver um conjunto de ideias. O que tá na lei muitas 
vezes não é o que na nossa realidade vai ser o mais viável, o mais justo e o mais sensato de se fazer. Então eu não sei, a gente tem que estar conversando e analisando o que dá pra se fazer. O que a pedagoga falou é que realmente o correto seria chamar pelo nome de registro dele, agora, se os pais quiserem, aí é outra situação. [...] Mas a gente vai decidir ainda, mas pelo que eu tô vendo e tá encaminhando, ele vai ser chamado pelo nome social dele [...] Porque ele falou pra mim que não vai fazer formatura se não for ser chamado por Melanie. Então, daí, como você faz? Você vai constranger o aluno? É isso que tá dizendo pra gente fazer na diversidade sexual? (ESCOLAC, BRIGITTE, DIRETORA).

$\mathrm{O}$ desentendimento entre equipe diretiva e pedagógica e a recusa em chamar a estudante travesti pelo seu nome social, em um evento de conclusão de curso, bem como pelo gênero com o qual ela se identifica, ensina e incentiva os/as demais alunos(as) a adotarem atitudes de hostilidade e de desrespeito às diferenças em geral, "[...] pode ser destacada como um símbolo de desempoderamento uma vez que implica em desapropriar o sujeito de seu próprio nome" (MOSCHETA, 2011, p. 52), bem como pela sua identidade de gênero pretendida.

Para Junqueira (2012, p. 78), esse é um dos meios mais eficientes "[...] de se traduzir a pedagogia do insulto no currículo em ação em processos de desumanização, estigmatização e exclusão e, assim, de reforçar ulteriormente os ditames que a pedagogia do armário exerce sobre todo o alunado".

Discursos similares aos da diretora Brigitte e da pedagoga Brida foram comumente encontrados durante nossa pesquisa, como nos relatos que seguem de uma professora e uma pedagoga de outra escola que também tinha uma travesti em seu corpo discente.

Rosa: Olha, antes ele [aluna travesti] [...] andava igual aos outros, de uniforme, e de repente ele assumiu, né, começou a vir, é... a se vestir igual travesti, vestido de mulher, usar pinturas [...]. Nós conversamos muito com ele [...] a escola exigia que ele viesse de uniforme porque é igual a todo mundo, né, mas ele usava pintura, maquiagem [...]

Entrevistador: E a escola o chamava por qual nome?

Rosa: Eu, como professora, chamava ele pelo nome de batismo. (ESCOLA A, ROSA, PROFESSORA).
A gente chamava ele pelo nome, Fernando, que o nome dele é Fernando, mas ele falou pra nós que ele gostaria que fosse chamado de Fernanda. Aí nós fomos nos informar, né, aí a orientação que nós tivemos era assim, que antes dos 18 anos ele tinha que usar o nome dele de certidão, depois dos 18 ele podia usar o nome social, o nome que ele achasse... que ele gostasse. (ESCOLA A, RUTH, PEDAGOGA).

A Secretaria de Educação do Estado do Paraná, localidade onde esta pesquisa foi realizada, defende que o nome social não é um capricho de um(a) aluno(a) travesti, transexual e transgênero, mas sim

[...] o reconhecimento de pertencimento da identidade de gêneros das/dos travestis e transexuais. Sendo assim, fica instituído o uso do mesmo a fim de garantir o acesso e a permanência dessa população em todos os estabelecimentos de ensino da Rede Pública Estadual do Paraná e, principalmente, para possibilitar a garantia do direito constitucional à educação pública e de qualidade a todas/os as/os cidadãs/os. (PARANÁ, 2010, p. 01).

Esse(a) aluno(a) deverá receber tratamento respeitoso e ético, de acordo com sua identidade de gênero (feminina ou masculina), por todas as pessoas envolvidas no ambiente escolar, desde seu primeiro contato e em todos os espaços e relações rotineiras. A comunidade escolar, incluindo aí professores(as), pedagogos(as), diretores(as), alunos(as), funcionários(as), deve garantir um tratamento solidário em todos os ambientes e ocasiões ao longo do processo de escolarização, pois chamar o/a aluno(a) travesti no feminino ou masculino não é um dado recente, mas sim uma decisão política e acadêmica advinda do

[...] movimento social que se organizou mais recentemente, principalmente depois dos anos 80, porque o que vai se considerar é que o gênero como construção social, como aquilo vivido no cotidiano, como a maneira que o/a travesti, transexual ou transgênero se apresenta e lida com as pessoas ao estabelecer suas relações é que vai ser definidor de quem a pessoa é e não a sua genitália. Essa definição biológica, naturalizante é menos relevante levando em conta que nós enquanto humanos somos seres sociais. (PELÚCIO, 2013).

A Orientação Pedagógica nº 001/2010 (PARANÁ, 2010) coaduna com este posicionamento ao estabelecer que a Rede Pública de Ensino Estadual 
de Educação Básica deverá incluir, após solicitação por escrito do(a) E.T., no ato da matrícula, o nome social no campo destinado para esse registro no cadastro do(a) aluno(a), bem como o sigilo aos documentos que constem seu nome civil. Dessa forma, o nome social será impresso automaticamente no espelho do Livro Registro de Classe, nos Editais e Boletins Escolares.

A escola não segue essa lógica e ainda cria outras barreiras quanto ao acesso e permanência de E.T. no espaço escolar. Esses(as) se deparam cotidianamente com outro fator agravante, quanto à aquiescência de sua identidade de gênero, quando precisam fazer uso de sanitários. Para Silva (2008, p. 13) "a rígida organização física de separação entre o masculino e o feminino marca a experiência destas pessoas tensionadas pela reprodução da heteronormatividade e pela resistência à ordem instituída".

O banheiro da escola é muito mais que um espaço reservado à realização de necessidades fisiológicas; ele é parte fundamental do processo de construção de identidades e reprodução das diferenças, e é neste espaço que os/as E.T. passam por constrangimentos, aversões e diversas outras formas de agressão e segregação.

Banheiro é uma coisa que eu tive que chamar pra conversar. Como que você tá usando o banheiro? Porque de homem não dá porque tá vestido de mulher. Né, você gosta de homem, e daí? Você vai ao banheiro das meninas, você é um homem fisicamente, e daí? (ESCOLA C, BRIGITTE, DIRETORA).

\section{Em outra escola a diretora afirma que}

[...] na questão do uso dos banheiros, ele não usava banheiro das meninas porque na verdade ele não era menina, e no banheiro dos meninos, os meninos colocavam que ele não queria, então nós aqui, a escola, é... arrumou, deixou pra ele um outro banheiro pra que ele fizesse uso. Então nessa questão, ali sim, até mães vieram pra escola, que como ele não é menino, como ele vai usar banheiro dos meninos?! [...] e os meninos não aceitavam que ele usasse o banheiro dos meninos. Então nós tivemos essa problemática, sim. (ESCOLA A, RACHEL, DIRETORA).

A professora da escola supracitada reafirma que

[...] nós conversamos muito com os alunos da escola, né. Ele reclamava que não podia usar o banheiro, não gostava de usar o banheiro do homem, e... quando ia ao das meninas, as meninas também não permitiam [...] As mães começaram a vir pra escola, daí o que que nós fizemos: conversamos muito com ele e ele começou a usar o banheiro dos professores pra tentar evitar um pouco dos conflitos, né! (ESCOLA A, ROSA, PROFESSORA).

Quanto ao uso de banheiros, os/as E.T. devem utilizar o sanitários das(os) alunas(os) de acordo com a identidade de gênero que apresentam. Dessa forma, a arquitetura da escola não precisará sofrer qualquer alteração, nem ser construído um terceiro banheiro, como tem sido defendido por alguns(mas) educadores(as). No mais, é orientado que não seja concedido o banheiro de professores(as) ou de pessoas com necessidades especiais (PARANÁ, 2010).

No entanto, o que se percebe nas escolas é a intenção inicial de se permitir a livre escolha do sanitários pelas(os) E.T., porém rapidamente há um recuo em sua decisão que passa a contrariar normativas estabelecidas por órgãos como a Secretaria da Educação do Estado de forma a manter a fraudulenta atmosfera de convivência pacífica com os sujeitos.

Aí, na questão, a gente tinha a questão do uso do banheiro, né, que deu um problema, porque daí ele ia ao banheiro dos meninos, aí tinha o banheiro das meninas e nós orientamos ele a usar o banheiro dos professores, né, pra não causar conflito né, aí... só que ele evadiu, né, ele estudou um período, né, daí ele se evadiu. (ESCOLA A, RUTH, DIRETORA).

A gente passou por esse momento de conversar com ela, conversar com a família dela, que a aceitação do uso do banheiro [ênfase]. Que os meninos não queriam porque ela se veste de mulher. As meninas não queriam porque ela ainda tem um órgão masculino. A gente cedeu o nosso [dos(as) professores(as)]. Houve um consenso de todos os professores e hoje ela usa o nosso banheiro. (ESCOLA B, BRANCA, PEDAGOGA).

Aí nós destinamos um outro banheiro, que é separado, então eles vão pra um outro banheiro sem causar constrangimento, né. (ESCOLA C, BRIGITTE, PEDAGOGA).

O abrandamento dos conflitos é justificado pelo incômodo dos(as) alunos(as) tidos(as) como "normais", ou heteronormatizados, com a 
presença de um(a) E.T. frequentando o mesmo ambiente privado que eles(as). Então, a solução encontrada, na maioria das vezes, é o contorno da situação de forma que aqueles(as) vistos(as) como desviantes possam satisfazer suas necessidades fisiológicas de maneira imperceptível, garantindo sua invisibilidade para a comunidade escolar. Assim, estrategicamente, a escola dispõe de um espaço alternativo lançando mão dos sanitários de docentes ou de alunos(as) com necessidades especiais.

A adoção de medidas como essas tende a minimizar os efeitos imediatos entre comunidade escolar e família, porém desconsidera completamente o sentimento de desprezo e o sofrimento psíquico aos quais são submetidos(as) os/as E.T. Bohm nos chama atenção em sua pesquisa para o relato de uma aluna travesti: "eu preferia ficar sem fazer xixi, apertada, a manhã toda a entrar em um dos banheiros" (BOHM, 2009, p. 59).

O que aparece em jogo no uso dos banheiros são trocas simbólicas de exercícios de identidade de gênero que são fortemente desempenhadas entre os grupos. As pessoas que não se encaixam nos polos separados e opostos da masculinidade ou feminilidade são excluídas do ritual ou incorporadas de forma subordinada, inferiorizada (SILVA, 2008).

É importante ressaltar que, tanto a arquitetura do banheiro feminino quanto masculino, historicamente, encontra-se organizada de forma a garantir a privacidade de quem o utiliza. É necessário que a escola crie estratégias de desestabilização e de problematização a fim de superar o preconceito e as práticas discriminatórias contra os(as) E.T.; isso perpassa a discussão de gênero no espaço escolar.

Urge a necessidade de reflexões acerca da existência de vários espaços públicos de uso coletivo por homens e mulheres; na esfera privada observamos que a maioria das famílias brasileiras tem por hábito utilizar o mesmo banheiro sem distinção de sexo. Por que na escola teria de ser diferente? (PARANÁ, 2010).

Quando esse assunto transpõe os muros da escola e chega até a família, tanto os/as E.T. quanto a escola passam a sofrer fortes interferências em seu funcionamento e no cumprimento dos direitos ao livre acesso.
Eu tenho que ouvir ela [aluna travesti], mas eu também tenho que ouvir aquele pai que não aceita que ela use o banheiro feminino, porque ela ainda tem o órgão masculino [...] porque se uma família vai para a Justiça, né, na questão enquanto ela não for maior de idade e não fizer todo o processo, ela tem que aceitar o que a escola tem a oferecer pra ela, que é o banheiro nosso [dos(as) professores(as)], porque até então ela queria usar o banheiro das meninas. (ESCOLA B, BRANCA, PEDAGOGA).

Sendo assim, os/as educadores(as) não são os/ as únicos(as) a ver com alguma preocupação o aparecimento em cena daquilo que podemos chamar de "alienígenas" ou simplesmente E.T., isto é, esses(as) "outros(as)" que se apresentam em nossas salas de aula.

Os pais e as mães também têm expressado esse tipo de preocupação, assim como tem feito, de forma mais geral, a esfera pública convencional (a opinião pública). Tem havido recentemente uma onda crescente de pânico moral, cujo foco é o suposto desvio da juventude contemporânea - não apenas sua diversidade ou sua diferença, mas, mais radicalmente, sua alteridade, e a ameaça que isso apresenta para o/a observador(a), para o olhar do ego, para o olhar do sujeito, para o eu. Esse desvio é oficialmente representado e construído não como a mudança que tão claramente parece ser, mas como uma questão de deficiência, de incompletude e de inadequação. O tom é fortemente apocalíptico e a mudança é concebida como patologia (GREEN; BIGUM, 1995).

A Orientação Pedagógica $n^{\circ}$ 001/2010 estabelece que, caso as recomendações por ela dispostas não sejam atendidas por qualquer estabelecimento de ensino público estadual, caberá à Secretaria Estadual de Educação (SEED) estabelecer medidas necessárias ao seu devido cumprimento, além disso, casos de preconceitos e discriminações contra os/ as E.T. deverão ser registrados junto à Ouvidoria dos Núcleos Regionais de Educação (NRE) e/ou SEED (PARANÁ, 2010).

Mesmo diante dessa normatização, a escola não aplicava na íntegra seus preceitos e o Núcleo Regional de Educação daquela localidade não fornecia subsídios para sua validação quanto à adoção de medidas não previstas na Orientação Pedagógica, como relatara uma diretora escolar: 
Nós ligamos no Núcleo Regional de Educação e foi perguntando de que maneira, de que jeito vai ser colocado isso [sobre o nome que deveria ser chamada a aluna travesti no momento da cerimônia de formatura]. Porque tem uma lei que diz assim, que até no livro de chamadas, se ele quiser mudar o nome social dele, nós temos que acatar e colocar o nome social dele. Quando a gente questiona o próprio Núcleo de Educação, até eles ficam perdidos muitas vezes, no que colocar que ampara a gente, né. Então, por lei, tá dizendo ali no livro de chamadas e tudo mais, agora numa formatura, numa ocasião social, ficaria mais a critério nosso também, de tá conversando e chamando os pais desse aluno e verificando com os pais, porque ele é menor, de que maneira que ele vai ser chamado. (ESCOLA C, BRIGITTE, DIRETORA).

O NRE, além de não possuir uma política de formação e apoio permanente a essas questões, mostrou-se também desconhecedor de normativas que regulamentam a inclusão do nome social nos ritos escolares.

\section{A evasão invisibilizada pelo fracasso escolar de Estudantes Trans}

Diante do que foi apresentado até o momento, o cotidiano escolar se configura num local de hostilidade para E.T. que, em sua grande maioria, "abandonam" os estudos. "[...] Não nos surpreende que alguns/mas dos/as entrevistados/as tenham se referido a problemas de desempenho escolar, manifestados em absenteísmo, reprovações sucessivas, abandono, etc.” (GÓIS; SOLIVA, 2011, p. 43) para justificar a evasão desses(as) alunos(as).

Os/as docentes entrevistados(as) associaram as constantes faltas de E.T. à reprovação e evasão escolar: "[...] ele já tinha problemas de faltas, a gente já tinha resgatado, mas depois dele ter completado 18 anos ele se evadiu" (ESCOLA A, RACHEL, DIRETORA).

Tal afirmativa invisibiliza a desmotivação que impele os/as E.T. - diante da recusa da comunidade escolar em entender o gênero como constituinte da identidade desses sujeitos; da tirania a que são submetidas(os) para se adequar às inúmeras regras de comportamento de gênero e da estigmatização dessas pessoas caracterizadas como "desviantes" e, em alguns casos, "anormais", numa sociedade em que prevalecem o binarismo e a heteronormativi- dade - e destitui dessas pessoas as possibilidades de viverem suas identidades (BORTOLINI, 2008; HALL, 2007; LOURO, 1997; SILVA, 2007).

Esses estigmas contribuem certamente para a cristalização de um sentimento nesses(as) alunos(as) de que não deveriam estar ali, pois são um incômodo permanente e que a única forma de superar esses obstáculos é sair da escola (HALL, 2007; LOURO 1997).

Encontramo-nos, nesse momento, frente ao complexo conceito de formação de identidade e subjetivação das diferenças, que pode ser formulado a partir de diferentes perspectivas. Aproximando-nos da teoria dos Estudos Culturais, compreendemos que os/as E.T. possuem identidades plurais e que a intolerância às suas diferenças podem levá-los(as) a distintas direções, e nem sempre os caminhos que lhes são apontados são os da continuidade do processo de escolarização (BORTOLINI, 2008; LOURO, 1997; SILVA, 2007).

Vítimas do processo de evasão escolar, os/as E.T. dificilmente conseguem concluir seus estudos, "[...] sendo forçadas (os) a abandonar a escola, já que diferentemente de adolescentes gays e lésbicas, têm mais dificuldade em esconder sua diferença, tornando-se as vítimas mais visíveis dessa violência escolar" (DINIS, 2011, p. 43).

Não pretendemos apontar a evasão sob o manto de invisibilidade, uma vez que o que chamamos até aqui de evasão pode ser traduzido em expulsão compulsória e consiste no "[...] desejo de eliminar e excluir aqueles que 'contaminam' o espaço escolar. Há um processo de expulsão, e não de evasão [...]” (BENTO, 2011, p. 555), ocasionado pela rejeição cotidiana ao modo de se vestir, às formas de agir e se portar, ao descumprimento de preceitos essenciais - como o uso do nome social - e o livre trânsito entre os espaços que compõem a escola.

Toda essa engrenagem limita as possibilidades de realização social e profissional de um(a) E.T. "[...] não por uma limitação pessoal, mas por uma máquina de exclusão que a empurra permanentemente para a marginalidade da vida social, o que as torna um segmento populacional extremamente vulnerável" (BORTOLINI, 2008).

Nesse sentido, é importante diferenciar "evasão" de "expulsão", pois, ao apontar com maior 
verossimilhança as causas que impelem os/as E.T. a não frequentarem o processo de escolarização, deparamo-nos com a intolerância alimentada pela transfobia. $\mathrm{O}$ resultado da expulsão compulsória reflete em dados estatísticos, como os publicados pelo Grupo Gay da Bahia (2011) no Relatório Anual de Assassinato de Homossexuais de 2010, no qual foram documentados 260 assassinatos de gays, travestis e lésbicas, no referido ano, sendo que, dentre os/as mortos(as), 110 eram travestis, o que corresponde a $42 \%$ das vítimas no Brasil.

\section{Para além de uma conclusão}

Assumindo os objetivos estabelecidos como ponto de partida para nossas discussões, no que se refere à construção da identidade de gênero de E.T. e como a cultura das diferenças se re/produz no contexto escolar, depreendemos que Estudantes Trans não passam incólumes ao processo de generificação ao arquitetarem seus corpos de acordo com a sua identidade de gênero, e são vítimas constantes do processo de heteronormatização por meio de um conjunto de estratégias sistematizadas que se manifestam através da transfobia pedagógica.

A transfobia escolar tende a desconsiderar os graves efeitos de subjetivação produzidos pelas suas estratégias e discursos que re/produzem identidades e diferenças, expondo E.T. a situações vexatórias de vulnerabilidade, expulsando-os(as) compulsoriamente da escola, sob a invisibilidade do pretexto de fracasso escolar, por não terem seus direitos básicos respeitados, sujeitando-os(as) à informalidade ou situações degradantes de sobrevida, quando não conseguem colocação no mercado de trabalho pela desqualificação profissional, aliando essas estratégias ao preconceito e à discriminação.

Não pretendemos negar a co/existência da(s) diferença(s) entre homens e mulheres. O que não podemos é contribuir para que essas diferenças sejam transformadas em desigualdades, principalmente enquanto agentes do contexto educacional, ao nos confrontarmos com a presença de estudantes trans.

Queremos reafirmar o direito das pessoas serem diferentes, em todos os sentidos, porém defendemos que essa diferença seja vista como algo que caracteriza a espécie humana, não simplesmente como algo a ser tolerado, uma vez que essa espécie de benevolência atribui aos sujeitos, com variáveis graus de preconceitos, uma dose de benignidade, pela compaixão que caridosamente destinam ao(à) E.T., ao permitir a sua coexistência - à margem, é óbvio - sem levar em conta a relação de poder que a sustenta.

Chamamos atenção do(a) nosso(a) leitor(a) para o fato de que vivemos um momento no qual todos nós somos agentes responsáveis por uma educação igualitária, portanto a escola não pode se isentar de seu papel na formação do ser social, possibilitando o exercício de uma cidadania plena. Como prerrogativa desse exercício é necessária a inserção de temas que causem impactos positivos e relevância na vida social de pessoas Trans.

Nesse sentido, defendemos a efetivação de estratégias pedagógicas, curriculares e de programas continuados de contestação sobre temas como a identidade de gênero, violência de gênero, transfobia, manifestações da sexualidade, dentre outros, e que esses se pautem não apenas na inclusão de professores(as), mas também de toda a comunidade escolar, de forma a evitar que o/a E.T. seja vítima da tirania e expulsão escolar compulsória.

Essas discussões devem ganhar espaço formal no processo nos livros, nos conteúdos didáticos e, principalmente, nas práticas pedagógicas. Defendemos a ideia de que a discussão sobre diversidade sexual e a promoção da cultura do respeito não deve ser pautada unicamente pela presença de E.T. no cotidiano escolar, mas porque tal conduta infere na realidade social marcando, regulando e normatizando pessoas por meio de uma conduta moral heteronormatizadora, que insistentemente se desdobra na violação de direitos e ocasiona os mais distintos prejuízos sociais, ao retirar do ato de viver o livre exercício dos distintos modos de ser e sentir-se humano.

Numa paráfrase a Foucault (2007), acreditamos que talvez a escola já tenha dado seus primeiros passos neste sentido, talvez ainda estejamos muito longe desse objetivo, talvez não cheguemos nunca a este objetivo e, às vezes, fica a dúvida se estamos ou não caminhando na direção adequada, mas sabemos que uma jornada começa a partir do primeiro passo. Lancemo-nos a ela. 


\section{REFERÊNCIAS}

ABRAMOVAY, Miriam (Coord.). Revelando tramas, descobrindo segredos: violência e convivência nas escolas. Brasília: Rede de Informação Tecnológica Latino-Americana - RITLA/Secretaria de Estado de Educação do Distrito Federal - SEEDF, 2009. Disponível em: <http://www.abglt.org.br/docs/Revelando_Tramas.pdf $>$. Acesso em: 04 jan. 2013.

BARDIN, Laurence. Análise de conteúdo. 4. ed. rev. atual. Trad. Luís Antero Reto e Augusto Pinheiro. Lisboa: Edições 70, 2010.

BEAUVOIR, Simone. O segundo sexo. Rio de Janeiro: Nova Fronteira, 1980.

BENTO, Berenice. Na escola se aprende que a diferença faz a diferença. Estudos Feministas, Florianópolis, v. 9, n. 2, p. 549-559, maio/ago. 2011.

BOHM, Alessandra Maria. Os "monstros" e a escola: identidade e escolaridade de sujeitos travestis. 2009. 103 f. Dissertação (Mestrado em Educação) Programa de Pós-Graduação em Educação, Universidade Federal do Rio Grande do Sul, Porto Alegre, 2009.

BORTOLINI, Alexandre. Diversidade sexual na escola. Rio de Janeiro: UFRJ, 2008.

BRASIL. Gênero e diversidade na escola: formação de professoras/es em Gênero, Orientação Sexual e Relações Étnico-Raciais. Livro de conteúdo. v. 1, versão 2009. Rio de Janeiro: CEPESC; Brasília: SPM, 2009.

Ministério da Saúde. Secretaria de Vigilância em Saúde. Departamento de DST, AIDS e Hepatites Virais. Adolescentes e jovens para uma educação entre pares: diversidades sexuais. v. 8. Brasília, DF, 2011.

BUTLER, Judith. Corpos que pesam: sobre os limites discursivos do "sexo". In: LOURO, Guacira Lopes (Org.). O corpo educado. Trad. Tomaz Tadeu da Silva. 3. ed. Belo Horizonte: Autêntica, 2010. p. 151-172.

CÉSAR, Maria Rita de Assis. Gênero, sexualidade e educação: notas para uma "Epistemologia". Educar em Revista, Curitiba, n. 35, p. 37-51, 2009.

DINIS, Nilson Fernandes. Homofobia e educação: quando a omissão também é signo de violência. Educar em Revista, Curitiba, n. 39, p. 39-50, jan./abr. 2011.

FOUCAULT, Michel. A ordem do discurso. 15. ed. São Paulo: Loyola, 2007.

GÓIS, João Bôsco Hora; SOLIVA, Thiago Barcelos. A violência contra gays em ambiente escolar. Revista Espaço Acadêmico, n. 123, p. 38-45, ago. 2011.

GREEN, Bill; BIGUM, Chris. Alienígenas na sala de aula. In: SILVA, Tomaz Tadeu da (Org). Alienígenas na sala de aula: uma introdução aos estudos culturais em educação. 5. ed. Petrópolis, RJ: Vozes, 1995. p. 208-243.

GRUPO GAY DA BAHIA. Epidemia do ódio. 2011. Disponível em <http://www.ggb.org.br/Assassinatos\%20 de\%20homossexuais\%20no\%20Brasil\%20relatorio\%20geral\%20completo.html $>$. Acesso em: 03 jan. 2012.

HALL, Stuart. A identidade cultural na Pós-modernidade. Trad. Tomaz Tadeu da Silva e Guacira Lopes Louro. 11. ed. Rio de Janeiro: DP\&A, 2006.

Quem precisa da identidade? In: SILVA, Tomaz Tadeu da (Org.). Identidade e diferença: a perspectiva dos Estudos Culturais. 7. ed. Petrópolis/RJ: Vozes, 2007. p. 103-133.

JUNQUEIRA, Rogério Diniz. Homofobia nas escolas: um problema de todos. In: (Org.). Diversidade sexual na educação: problematizações sobre a homofobia nas escolas. Brasília, DF: Ministério da Educação/ Secad, 2009. p. 13-52.

A Pedagogia do Armário: heterossexismo e vigilância de gênero no cotidiano escolar. Revista Educação On-line PUC, Rio de Janeiro, n. 10, p. 64-83, 2012.

LIONÇO, Tatiana. DINIZ, Debora. Qual a diversidade sexual dos livros didáticos brasileiros? In:

Homofobia \& Educação: um desafio ao silêncio. Brasília: EdUnB, 2009. p. 09-13.

(Org.).

LOURO, Guacira Lopes. Gênero, sexualidade e educação. Uma perspectiva pós-estruturalista. Petrópolis, RJ: Vozes, 1997.

Gênero e sexualidade: pedagogias contemporâneas. Pro-Posições, v. 19, n. 2, p. 17-23, maio/ago. 2008. 
MOORE, Henrietta L. Fantasias de poder e fantasias de identidade: gênero, raça e violência. Cadernos Pagu, $\mathrm{n}$. 14, p. 13-44, 2000.

MOSCHETA, Murilo dos Santos. Responsividade como recurso relacional para a qualificação da assistência a saúde de lésbicas, gays, bissexuais, travestis e transexuais. 2011. $213 \mathrm{f}$. Tese (Doutorado em Ciências) - Programa de Pós-Graduação em Psicologia, Faculdade de Filosofia, Ciências e Letras da Universidade de São Paulo (USP), Ribeirão Preto, 2011.

OLIVEIRA JÚNIOR, Isaias Batista de. O/a diretor/a não viu, a pedagoga não ouviu e a professora não quer falar: discursos docentes sobre diversidade sexual, homofobia e "Kit Gay". 2013. 260 f. Dissertação (Mestrado em Educação) - Programa de Pós-Graduação em Educação, Universidade Estadual de Maringá. Maringá, PR, 2013.

PARANÁ. Secretaria de Estado da Educação. Superintendência da Educação. Departamento da Diversidade. Orientação pedagógica $\mathbf{n}^{0} \mathbf{0 0 1} / \mathbf{2 0 1 0}$. Curitiba, 2010.

PELÚCIO, Larissa. Homossexualidade e orientação sexual. Programa Diálogos. TV UNESP. 2013. Disponível em: <http://www.youtube.com/watch?v=UD4945XmGGY>. Acesso em: 16 jan. 2013.

SAYÃO, Yara. Orientação sexual na escola: os territórios possíveis e necessários. In: AQUINO, Júlio Groppa. Sexualidade na escola: alternativas teóricas e práticas. São Paulo: Summus, 1997. p. 107-118.

SCHULMAN, Michael. Assexuados, bichas \& cia: a nova geração gay nas universidades dos EUA. Trad. Clara Alain. Folha de S. Paulo, São Paulo, 17 de fev. de 2013. Caderno Ilustríssima, Seção Comportamento.

SILVA, Joseli Maria. A cidade dos corpos transgressores da heteronormatividade. Geo UERJ, v. 1, n. 18, p. 01-17, 2008.

SILVA, Tomaz Tadeu da. A produção social da identidade e da diferença. In: perspectiva dos Estudos Culturais. 7. ed. Petrópolis, RJ: Vozes, 2007. p. 73-102. Identidade e diferença: a

SOUSA FILHO, Alípio de. A resposta gay. 2013. Disponível em: <http://www.cchla.ufrn.br/alipiosousa/index_arquivos/ARTIGOS\%20ACADEMICOS/ARTIGOS_PDF/A\%20RESPOSTA\%20GAY.pdf>. Acesso em: 07 jan. 2013.

SWAIN, Tania Navarro. Entre a vida e a morte, o sexo. 2009. Disponível em: $<$ http://intervencoesfeministas. mpbnet.com.br/textos/tania-entre_a_vida_ea_morte.pdf $>$. Acesso em: 13 jul. 2013.

Recebido em: 01.11.2015

Aprovado em: 02.03.2016 